\title{
Miswak (Salvadora persica) Roots as Antimicrobial and a Potential bioactive component
}

\author{
Abd-Aziz Nadir ${ }^{1}$, Ahmed A. Farrag' ${ }^{2}$ Eman A. Helmy ${ }^{3}$ and Asmaa S. Ismail ${ }^{4}$ \\ ${ }^{I}$ Food Technology Department, National Research Centre, Dokki, Giza, Egypt. \\ ${ }^{2}$ Nutrition and Food Science Department, Faculty of Home Economics, Helwan University Cairo, \\ Egypt. \\ ${ }^{3}$ Microbiolgy Department, the Regional Center for Mycology and Biotechnology, Al-Azhar University, \\ Cairo, Egypt \\ ${ }^{4}$ National Institute of the Nerve-Motor System - Ministry of Health, Egypt
}

Received: 10 Oct. 2019 / Accepted 12 Dec. 2019 / Publication date: 30 Jan. 2020

\begin{abstract}
Miswak contains important photo-constituents such as vitamin C, salvadorine, salvadourea, alkaloids, trimethylamine, cyanogenic glycosides, tannins, saponins and salts mostly as chlorides, in addition to Sulphur, organic Sulphur compounds and lignan glycosides. Pharmacological studies indicated that, S. persica L. plant possess anti-microbial, anti-plaque, aphrodisiac, alexiteric, analgesic, anti-inflammatory, anti-pyretic, astringent, diuretic and bitter stomachic activities , anticonvulsant ,and Antiulcer activity , hypoglycemic effect and it reduced body weight as well as the biological effects of Salvadora persica extracts are reviewed. The aim of this study were to evaluation the antimicrobial effect of (10\%) water, hexane and ethanol extracts of stem of plant Salvadora persica L.(Miswak) against various foodborne pathogens including(Staphylococcus aureus, Escherichia coli, Pseudomonas aeruginosa, Salmonella, Bacillus subtilis, Enterococcus faecalis, Aspergullus niger, Aspergullus flavius, Candida lipolytica and Candida albicans). Minimum inhibitory concentrations (MICs) .Concerning the in vitro antioxidant activities of the investigated Salvadora persica L. stem indicated by Mass spectrometry using (DPPH) assay technique. The water extract of Salvadora persica L. Were quantified using Folin-Ciocalteu and 2,2-diphenyl-1-picrylhydrazyl radical scavenging assay showed that the water extract had the highest levels of polyphenols Such outcomes corresponded intimately with the levels of aggregate phenols, flavones in tests.
\end{abstract}

Keywords: Water extract, hexane and ethanol extracts of Salvadora persica L. Polyphenols, Antioxidant and miswak

\section{Introduction}

Salvadora persica L. (Arak) tree and locally called Miswak belongs to Salvadoracea family, which grows in different area of the world including the Middle East and Africa, it is one of the most commonly used medicinal plants for oral hygiene among global Muslim community (Sher et al., 2010). It contains important phyto-constituents such as Vitamin C, Salvadorine, Salvadorurea, alkaloids, Trim ethylamine, Cyanogenic glucosides, Tannins, Saponions and salts mostly as chlorides.(Alali et al., 2004) The history and the use of miswak (tooth sticks) as an oral tooth as well as the biological effects of Salvadora persica, extracts reviewed. Variety of studies have been performed on the antimicrobial effect of these sticks of Salvadora persica, it has been shown various biological properties including significant antibacterial (Almas 2001).Antifungal (Al-Bagieh et al., 1994). Through suppress or destroy microbial growth, thus susceptibility of the microorganisms, penetration of antimicrobial agent to the infected site (Al-Salman et al., 2005). Others (Mohamed et al., 2012) found that alcoholic and water extracts of Salvadora persica inhibite the growth of Streptococcus pyogens, Staphylococcus aureus, E. coli and Pseudomonas aeruginosa.

Al-lafi and Ababneh, (1995), found that benzyl thiocyanate present in Salvadora persica inhibited the growth of Streptococcus mulans and suggested that Salvadora persica decreases the incidence of dental caries. While others (Mohamed et al., 2012) and (Khalil, 
2006) found the active component of Salvadora persica has a great antimicrobial activity against various Gram positive and Gram-negative bacteria.

The aim of this study the evaluation of antioxidant activity and the antimicrobial activity for water, hexane and ethanol Salvadora persica (Miswak) extracts. Which, then determined against some of food-associated microorganisms such as (E-coli, Salmonella spp, pseudomonas, Staphylococcus aureus, Bacillus cereus, enterococcus faecalis, Aspergillus flavusm, Aspergillus niger, Candida albicans, and candida lipolytic) and the minimum inhibitor concentration MIC for different extracts.

\section{Materials and Methods}

\section{Plant Material}

Dried roots of $S$. persica purchased from a local market in Jazan city, KSA, cut in 2015-2016 season. The extracts centrifuged at $3000 \mathrm{rpm}$ for $15 \mathrm{~min}$. Then, supernatants sterilized by passing through filter paper $\left(0.45 \mu \mathrm{m}\right.$ pore size) and then stored at $4 \mathrm{C}^{\mathrm{o}}$ until used within one week (AbdEl-Rahman et al., 2002).

\section{Microorganisms}

A total of ten microbial strains including Staphylococcus aureus, Escherichia coli, Pseudomonas aeruginosa, Salmonella, Bacillus subtilis, Enterococcus faecalis, Aspergullus niger, Aspergullus flavius, Candida lipolytica and Candida albicans used in the presented study. These strains obtained from The Regional Center for Mycology and Biotechnology, AL-Azhar University Egypt.

\section{Chemicals}

All chemicals and reagents used in the analytical methods were (analytical grade) produced by sigma chemical co. (St. Louis, mo., (USA) and purchased from EL. Gomhouria trading chemicals and drugs co.

\section{Preparation of (water, Ethanol, Hexane) of Miswak Root Extracts}

Water, Ethanol and Hexane Miswak root extracts (AMREs). Preparation Air-dried roots of Miswak cut into small pieces and grounded with a grinding machine into powder. Two quantities, each ten grams of powdered dried root Miswak (dry weight) were macerated in $100 \mathrm{ml}$ of sterile de-ionized water, Ethanol or Hexane(ratios $10 \%, \mathrm{w} / \mathrm{w}$ ) in sterile screw capped bottles at $40 \mathrm{oC}$ for $24 \mathrm{hr}$ to obtain extracts. Then steps followed as described by Finegold and Martin (1982).

\section{Determination of antimicrobial activity for extracts}

The antimicrobial effect of Miswak, extracts (water, Ethanol, Hexane) on growth of gram-negative bacteria (Escherichia coli, Salmonella spp., pseudomonas.), gram-positive bacteria (Staphylococcus aureus, Bacillus subtilis, and enterococcus faecalis), fungi (Aspergillus nigar, Aspergillus flavus) and yeasts (Candida ablicans, candida lypolitica) studied.

\section{A- Antibacterial activity for extracts}

Antibacterial activity of the tested strains detected using the agar diffusion test according to the method mentioned by Pundir et al. (2010). The antibacterial activity of water, hexane and ethanol extracts evaluated by using agar well diffusion method. Plate count agar (PCA) plates inoculated with $100 \mu \mathrm{l}$ of standardized inoculum $(1.5 \times 108 \mathrm{CFU} / \mathrm{ml})$ of each selected bacterium (in triplicates) and spread with sterile swabs. Wells or cups of 8 $\mathrm{mm}$ size were made with sterile borer into agar plates containing the bacterial inoculum and the lower portion was sealed with a little molten agar medium. 100 $\mu \mathrm{l}$ volume of the Miswak extracts poured into a well of inoculated plates. Chemical preservative sodium nitrite used as a positive control, which introduced into a well instead of Miswak extracts. Solvent, ethanol used as a negative control, which introduced into a well instead of different Miswak 
extracts. The plates thus prepared left at room temperature for ten minutes allowing the diffusion of the extract into the agar. After incubation for 24 hours at $37^{\circ} \mathrm{C}$, the plates observed. If antibacterial activity was present on the plates, it indicated by an inhibition zone surrounding the well containing the Miswak extracts. The zone of inhibition measured and expressed in millimeters. The mean and standard deviation of the diameter of inhibition zones were calculated.

\section{B- Antifungal activity for extracts}

The antifungal activity of Miswak extracts evaluated by using poisoned food technique. In poisoned food technique, according to the method mentioned by Pundir et al. (2010). All fungi inoculated on Potato dextrose agar (PDA) plates and incubated for $25 \mathrm{C}^{\circ}$ for 3 to 7 days, to obtain young, actively growing colonies of molds. A mycelial disc $6 \mathrm{~mm}$ diameter, cut out from periphery of three to7-day old cultures, was aseptically inoculated onto the agar plates containing the 3 different extracts.

\section{Determination of the minimum inhibitory concentrations of miswak extracts}

The minimum inhibitory concentrations (MICs) for different miswak extracts had determined by agar diffusion method. The agar plates containing medium composed of double strength Muller Hinton plus one of the following of each extract (water, ethanol and hexane). The tested bacterial strains (104/spot) inoculated onto the surfaces of the agar plates by using the multipoint inculcator. The plates then, incubated at $37 \mathrm{oC}$ for $24 \mathrm{hr}$ before defining the MICs.

\section{Determintion of Antioxidant properties}

\section{Antiradical activity}

The scavenging activity against DPPH radical was determined in this studyaccording to Brand-Williams et al. (1995). The radical scavenging activity (RSA) of Miswak extracts was expressed in terms of percentage inhibition of DPPH radical by Miswak extracts and was calculated according to (Batrušaityte et al., 2007) as follows:

RSA (DPPH. Inhibition, \%) $=[(\mathrm{AB}-\mathrm{AT}) / \mathrm{AB}] \times 100$

Where, $\mathrm{AB}=$ Absorbance of radical blank (DPPH without Miswak extracts)

$\mathrm{AT}=$ Absorbance of test sample (DPPH with Miswak extracts).

\section{Total flavonoid content.}

Total flavonoid was determined using the method of Meda et al. (2005) with minor modifications. In brief, $0.25 \mathrm{~mL}$ of sample $(0.1 \mathrm{mg} / \mathrm{mL})$ was added to a tube contained 1 $\mathrm{mL}$ of double-distilled water followed by $0.075 \mathrm{~mL}$ of $5 \% \mathrm{NaNO} 2,0.075 \mathrm{~mL}$ of $10 \%$ $\mathrm{AlCl} 3$ and $0.5 \mathrm{~mL}$ of $1 \mathrm{M} \mathrm{NaOH}$ at 0,5 and $6 \mathrm{~min}$, sequentially. Finally, the volume of the reaction solution was adjusted to $2.5 \mathrm{~mL}$ with double-distilled water. The absorbance of the solution was measured at $410 \mathrm{~nm}$ wave length in a spectrophotometer. Caffeic acid is a ubiquitous flavonoid was used as a standard to quantify the total flavonoid content of ethanol extract of Miswak extract and the results were expressed in microgram Catechin equivalents $(\mathrm{CE}) \mathrm{mg} / 10 \mathrm{~g}$ propolis.

\section{Total phenolic content (TP)}

Total flavonoid contents of Miswak extracts were determined by using the aluminum chloride colorimetric method with some modifications. $1000 \mu \mathrm{L}$ of each Miswak extracts (5gm Miswak extracts $/ 5$ methanol), $300 \mu \mathrm{L}$ (10\%) aluminum chloride, $300 \mu \mathrm{L}$ (5\%) sodium nitrite and $4.3 \mathrm{~mL}$ distilled water were mixed. After incubation at room temperature for 30 min, the absorbance measured at $415 \mathrm{~nm}$ by using a spectrophotometer (Shimadzu, Kyoto, Japan). Catching used to make the calibration curve (Quettier-Deleu et al., 2000). The determination of total flavonoids in the extracts carried out in triplicate and the results averaged. 


\section{Statistical analysis}

The results obtained in the present work are represented as means \pm standard error, and were analyzed using analysis of variance (ANOVA). The significance of difference between means at $\mathrm{P}<0.05$ was calculated using the Duncan Multiple Range Test (Steel and Torrie, 1980).

\section{Results and Discussion}

\section{Antimicrobial activity for extracts:}

The antimicrobial activity of water, hexane and ethanol miswak extracthas determined against some of food-associated microorganisms such as (E-coli, Salmonella spp, pseudomonas, Staphylococcus aureus, Bacillus cereus, enterococcus faecalis, Aspergillus flavusm, Aspergillus niger, Candida albicans, candida lypolitica) by using agar diffusion method. Results presented in table (1). The data indicated that in the agar well diffusion test, the sensitivity to the extracts of Miswak found change among the test organisms compared to the sodium nitrate as (positive control). Also, present investigation showed inhibitory activity against all the tested food associated microorganisms in which the diameter of zone of growth inhibition varied between $(2 \mathrm{~mm}$ ) for ethanol extract on E. coli was ( 29 $\mathrm{mm}$ ) for water extract on Candida ablicans. Generally miswak water extract given high inhibition zone than Miswak ethanol, hexane extract and sodium nitrite (NaNo3). On other hand gram negative bacteria as salmonella spp had $(30 \mathrm{~mm})$ high effected by water extract than gram-positive bacteria as Bacillus subtilis was $(15 \mathrm{~mm})$. In addition, candida ablicans had $(29 \mathrm{~mm})$ but Aspergillus niger had $(12 \mathrm{~mm})$ however Aspergillus niger had $(22 \mathrm{~mm})$ affected by ethanol extract more than water and hexane. Sodium nitrite not given any effect on (E. coli, Enterococcus faecalis, Bacillus subtilis and Aspergillus flavus)

Table 1: Effect of Different Miswak Extracts (Water, Ethanol and Hexane) on Growth of The Tested Microorganisms.

\begin{tabular}{|c|c|c|c|c|c|c|c|c|c|c|}
\hline \multirow{3}{*}{ Sample } & \multicolumn{10}{|c|}{ Inhibition zone $(\mathrm{mm})$} \\
\hline & \multicolumn{3}{|c|}{ Gram-negative } & \multicolumn{3}{|c|}{ Gram-positive } & \multicolumn{4}{|c|}{ Fungi } \\
\hline & $\begin{array}{c}\text { Ps. } \\
\text { aurg. }\end{array}$ & $\begin{array}{c}E- \\
\text { coli }\end{array}$ & $\begin{array}{c}\text { Salmo. } \\
\text { spp }\end{array}$ & $\begin{array}{c}\text { Staphylo. } \\
\text { aureus }\end{array}$ & $\begin{array}{c}\text { Bacillus } \\
\text { subtilis }\end{array}$ & $\begin{array}{l}\text { Entero. } \\
\text { faecalis }\end{array}$ & $\begin{array}{c}\text { Aspergillus } \\
\text { flavus }\end{array}$ & $\begin{array}{c}\text { Aspergillus } \\
\text { niger }\end{array}$ & $\begin{array}{l}\text { Candida } \\
\text { ablicans }\end{array}$ & $\begin{array}{l}\text { Candida } \\
\text { lypolitic }\end{array}$ \\
\hline WEM (water) & 21.5 & 25 & 30 & 19 & 14 & 16 & 12 & 20 & 29 & 15 \\
\hline EEM (ethanol) & 15 & 2 & 7 & 7 & 4 & 8 & 22 & 8 & 5 & 3 \\
\hline HEM (hexane) & 13 & 19 & 15 & 10 & 13 & 14 & 10 & 10 & 9 & 13 \\
\hline NaNO3(200ppm) & 12 & na & 16 & 14 & na & na & na & 11 & 16 & 14 \\
\hline
\end{tabular}

*Means with the same superscripts at the same column are not significant at $(\mathrm{p}<0.05)$

WE $M=$ water extract of miswak;

E E M=ethanol extract of miswak;

$\mathrm{HE} \mathrm{M}=$ hexane extract of miswak and $\mathrm{NaNO}_{3}=$ sodium nitrite

\section{Minimum inhibitory concentrations of miswak extracts}

Table (2) shows the minimum inhibitory concentration (MIC) (mg/mL soluble extract) as (\%percentage) values of plant extracts displaying a high antibacterial activity against different strains tested. The MIC values varied from $(0.19) \mathrm{mg} / \mathrm{mL}$ by water extract on (Salmonella. Spp) to (0.61) $\mathrm{mg} / \mathrm{mL}$ by ethanol extract on (E. coli) in (Table 2) while reached to (3.2) with sodium nitrite on (Staphylococcus. Aurous and Enterococcus faecalis). Water extract of Miswak significantly have a minimum inhibitor concentration at all microorganisms despite on (Pseudomonas aeruginosa) $(23 \mathrm{mg} / \mathrm{ml}$ ) and (Aspergillus flavus) $(0.22 \mathrm{mg} / \mathrm{ml})$ ethanol extract of Miswak had lower concentration than the water extract and comparison to positive control (NaNo3) as a common preservative to protect food products from microorganisms.

\section{Antioxidant properties}

Many studies conducted on plants which are rich in phenolic compounds often indicated that, they had some antimicrobial activity against various other bacteria involved in numerous oral diseases such as (gingivitis, periodontitis and dental caries) (Kumar et al., 2016). However, this result had not found evidence that polyphenols of Salvadora persica L. collected in South of Algeria exerted inhibitory effect on the growth of Streptococcus. 
This is true even at high concentrations of ethanol extract of the stem. These findings are in contrast to those reported by several researchers (Bhat et al., 2012). They observed a remarkable antimicrobial effect of both alcoholic and aqueous extracts of miswak on Streptococcus reputed to be the most cariogenic microbial species. It very well established that polyphenols can affect the growth of germs especially by inhibiting the activity of certain enzymes such as glucosyl transferase (GTFs) which is caused by reducing the phenomenon of adsorption of GTFs on the bacterial cell144. It also appears that, some catechins may even damage the membrane structures of the bacteria133. It appears that, most of the major antimicrobial compounds analyzed such as chlorogenic acid, flavanols (kaempferol, quercetin and catechin) and flavanones (naringenin) only found at low levels in the different extraction solutions of Salvadora persica. These bioactive substances did not affect the growth of Streptococcus.

Table 2: The minimum inhibitory concentrations (MIC) as percentage $(\%)$ of $(\mathrm{mg} / \mathrm{ml})$ for miswak (Salvadora persica) root extracts

\begin{tabular}{|c|c|c|c|c|c|}
\hline \multirow{2}{*}{\multicolumn{2}{|c|}{ Types of microorganisms }} & \multicolumn{4}{|c|}{$\begin{array}{l}\text { (\% of Inhibition for Miswak) by different solvent (water, ethanol } \\
\text { and hexane) }\end{array}$} \\
\hline & & NaNO3 (200ppm) & Water & Ethanol & Hexan \\
\hline \multirow{3}{*}{$\begin{array}{l}\text { Gram- } \\
\text { negative }\end{array}$} & Ps.aurg. & $0.33^{\mathrm{a}} \pm 0.08$ & $0.33^{\mathrm{c}} \pm 0.07$ & $0.23^{\mathrm{a}} \pm 0.02$ & $0.46^{\mathrm{c}} \pm 0.04$ \\
\hline & $E$-coli & $0.38^{\mathrm{bc}} \pm 0.07$ & $0.29^{\mathrm{bc}} \pm 0.04$ & $0.61^{\mathrm{e}} \pm 0.07$ & $0.27^{\mathrm{a}} \pm 0.02$ \\
\hline & Salmo. spp & $0.36^{\mathrm{b}} \pm 0.05$ & $0.19^{\mathrm{a}} \pm 0.05$ & $0.30^{\mathrm{b}} \pm 0.05$ & $0.40^{b} \pm 0.04$ \\
\hline \multirow{3}{*}{$\begin{array}{l}\text { Gram- } \\
\text { positive }\end{array}$} & Staphylo. aureus & $3.2^{\mathrm{e}} \pm 0.12$ & $0.29^{\mathrm{c}} \pm 0.02$ & $0.30^{\mathrm{b}} \pm 0.04$ & $0.51^{\mathrm{d}} \pm 0.04$ \\
\hline & Bacillus subtilis & $0.40^{c} \pm 0.06$ & $0.39^{\mathrm{c}} \pm 0.03$ & $0.49^{\mathrm{cd}} \pm 0.02$ & $0.46^{\mathrm{c}} \pm 0.04$ \\
\hline & Entero. faecalis & $3.2 \mathrm{e} \pm 0.14$ & $0.31^{\mathrm{bc}} \pm 0.04$ & $0.48^{\mathrm{cd}} \pm 0.03$ & $0.40^{b} \pm 0.03$ \\
\hline \multirow{2}{*}{ Fungi } & Aspergillusflavus & $0.29^{\mathrm{a}} \pm 0.03$ & $0.35^{\mathrm{cd}} \pm 0.01$ & $0.22^{\mathrm{a}} \pm 0.04$ & $0.51^{\mathrm{d}} \pm 0.05$ \\
\hline & Aspergillusniger & $0.40^{c} \pm 0.01$ & $0.25^{b} \pm 0.02$ & $0.28^{\mathrm{b}}$ & $0.52^{\mathrm{d}} \pm 0.05$ \\
\hline \multirow{2}{*}{ Yeasts } & Candida ablicans & $0.32^{\mathrm{ab}} \pm 0.03$ & $0.25^{\mathrm{b}} \pm 0.03$ & $0.44^{\mathrm{c}} \pm 0.05$ & $0.58^{\mathrm{e}} \pm 0.24$ \\
\hline & Candida lypolitic & $0.55^{\mathrm{d}} \pm 0.04$ & $0.35^{\mathrm{cd}} \pm 0.03$ & $0.52^{\mathrm{d}} \pm 0.03$ & $0.41^{\mathrm{b}} \pm 0.04$ \\
\hline
\end{tabular}

*Means with the same superscripts at the same column are not significant at $(\mathrm{p}<0.05)$

\section{Total phenolic content (TP)}

Phenolic compounds are antioxidants, which act as free radical terminators (Shahidi and Wanasundara, 1992). The statistical analysis carried out on all extracts showed that there was no correlation between antioxidant activity and total phenolic and flavonoid contents $(\mathrm{R} 2<0.1)$. Such a correlation reported by some studies. (Oktay et al., 2003; Shan et al., 2005; Pourmorad et al., 2006) and denied by others (Czapecka et al., 2005 and Wong et al., 2006). In fact, other antioxidants such as vitamins (A, $\mathrm{C}$, and $\mathrm{E}$ ), minerals (Selenium), carotenoids (betacarotene, lycopene) and polyphenols described in foods (Heinonen et al., 1998; Bartolome et al., 2004). As it was postulated before (Shan et al., 2005), we think that discrepancies between results from many studies are likely to be due to the genotypic and environmental differences within species, the choice of parts tested, the harvesting method and the antioxidant test used.

Table 3: Antioxidant activity and phytochemical composition of Miswak extract

\begin{tabular}{lccc}
\hline Propolis samples & DPPH (Inhibition ratio \%) & Total Phenolic content $\mathbf{~ m g} / \mathbf{k g}$ & $\begin{array}{c}\text { Total flavonid content } \\
\mathbf{~ m g} / \mathbf{k g}\end{array}$ \\
\hline Miswak extract & $82.62^{\mathrm{a}} \pm 0.2$ & $652.5^{\mathrm{a}} \pm 0.05$ & $7.26^{\mathrm{a}} \pm 0.04$ \\
\hline
\end{tabular}

*Means with the same superscripts at the same column are not significant at $(\mathrm{p}<0.05)$

\section{Conclusion}

The results significantly showed that salvadora persica L. stem, root and park extracts have abroad spectrum activity against a panel of bacteria and fungi responsible for most food born microbe. This activity may be due to high level of total flavonoid and phenolic content as an antioxidant effect. Water extract of Miswak have best results than ethanol and $n$-hexane so we can replace the artificial chemical substance as (sodium nitrite 
NaNo3) to food preservation by natural and healthy extracts as water Miswak extract (10\%) to enhance the general health.

\section{References}

Abd-elrahman, H., N. Skaug and W.F. George, 2002. In vitro antimicrobial effects of crude miswak extracts on oral pathogens. The Saudi Dental Journal, (14) 2632.

Alali, F., M. Hudaib, T. Aburjai, K. Khairallah and N. Al-Hadidi, 2004. GC-MS analysis and antimicrobial activity of the essential oil from the stem of the Jordanian toothbrush tree Salvadora persica, Pharmace. Biol., 42(8): 577-580.

Al-Bagieh, N.H., A. Idowu, and N.O. Salako, 1994. Effect of aqueous extract of Miswak on growth of Candida albicans in vitro, Microbio. Lett., 80: 107-113.

Al-lafi, T. and H. Ababneh, 1995. The effect of the extract of Miswak (chewing sticks) used in Jordan and the Middle East on oral bacteria. Int. Dent. J., 45: 218-222.

Almas, K., 2001. The antimicrobial effects of seven different types of Asian chewing sticks, OdontoStomatology Tropical, 96:17-20.

Al-Salman, T.H., A. Al- Shaekh, Al- Nu and O. Aimy, 2005. The antimicrobial effect of water extraction of Salvadora persica (Miswak) as a root canal irrigant, Al-Rafidain Dent. J., 5(1): 33-36.

Baltrušaityte, V., P. R. Venskutonis, and V. Čeksteryte, 2007: Radical scavenging activity of different floral origin honey and beebread phenolic extracts. Food Chemistry, 101(2): 502-514. https://doi.org/10.1016/j.foodchem.2006.02.007

Bartolome, B., V. Nunez, M. Monagas and C. Gomez-Cordoves, 2004. In vitro antioxidant activity of red grape skins, European Food Research Technology, 218:173-177.

Bhat, P. K., A. Kumar, and S. Sarkar, 2012. Assessment of immediate antimicrobial ffet of miswak extract and toothbrush on cario genic bacteria-Aclinical study. J. Adv. oral Res., 3:25-52.

Brand-Williams, W., M.E. Cuvelier, and C. Berset, 1995. Use of free radical method to evaluate antioxidant activity. Lebensmittel-Wissenschaft und-Technologie, 28:25-30.

Czapecka, E., A. Mareczek and M. Leja, 2005. Antioxidant activity of fresh and dry herbs of some Lamiaceae species. Food Chemistry, 93: 223-226.

Finegold, S.M. and M.J. Martin, 1982. Diagnostic Microbiology. 6th Ed. The C.V. Morsby Co., London, Ch. 20: 199-230.

Heinonen, M., P.J. Lehtonen and A. Hopla, 1998. Antioxidant activity of berry and fruit wines and liquor. Journal of Agricultural and Food Chemistry, 48: 25-31.

Khalil, A.T., 2006. Benzyl amides from Salvadora persica, Archives of Pharmacal Research, 29: 952956.

Kumar, S., N.S.S. Gautam, and V. Kumar, 2016. prliminary phyto chemical screening and antimicrobial activity of salvadora peersica linn.xtracts against oral pathogens.fungal Genom.Biol.,vol.610.4172/2165-8056.

Meda, A., C. E. Lamien, M. Romito, J. Millogo, and O. G. Nacoulma, 2005. Determination of the total phenolic, flavonoid and proline contents in Burkina Fasan honey, as well as their radical scavenging activity. Food Chemistry, 91: 571-577. http://dx.doi.org/10.1016/j. foodchem.2004.10.006

Mohamed, S. A., A. L. Al- Malki, J. A. Khan, M. J. Sulaiman, and T. A. Kumosani, 2012. Properties of peroxidase from chewing stick Miswak, African J. Pharmacy and Pharmacology; 6(9): 660670.

Oktay, M., I. Gulcin, and O.I. Kufrevioglu, 2003. Determination of in vitro antioxidant activity of fennel (Foeniculum vulgare) seed extracts., Lebensmittel-Wissenschaft und-Technologie, 36: 263-271.

Pourmorad, F., S. J. Hosseinimehr and N. Shahabimajd, 2006. Antioxidant activity, phenol and flavonoid contents of some selected Iranian medicinal plants, African Journal of Biotechnology, 5, , (11) 1142-1145.

Pundir, R. K., P. Jain, and C. Sharma, 2010. Antimicrobial Activity of Ethanolic Extracts of Syzygiumaromaticum and Alliumsativum against Food Associated Bacteria and Fungi. Ethnobotanical Leaflets, 14: 344-60. 
Quettier-Deleu, C., B. Gressier, J. Vasseur, T. Dine, C. Brunet, and M. Luyckx, 2000. Phenolic compounds and antioxidant activities of buckwheat (Fagopyrum esculentum Möench) hulls and flour. Journal of Ethnopharmacology, 72: 35-42.

Shahidi, F., and P. K. J. P. D. Wanasundara, 1992. Phenolic antioxidants. Critical Reviews in Food Science and Nutrition, 32: 67-103.

Shan, B., Y.Z. Cai, M. Sun, and H. Corke, 2005. Antioxidant capacity of 26 spice extracts and characterization of their phenolic constituents. Journal of Agricultural and Food Chemistry, 53: (20) 7749-7759.

Sher, H., M.N. Al-Yemeni, S.M. Yahya, and H.S. Arif, 2010. Ethno medicinal and ecological evaluation of Salvadora persica L. a threatened medicinal plant in Arabian Peninsula, J. Med. Plants Res., 4(13):1209-1215.

Steel, R. G. D., and J. H. Torrie, 1980. Principles and procedures of statistics a biometrical approach. Mc- Graw-Hill Book Publishing Company, New York.

Wong, C., H. Li, K. Cheng, and F. Chen, 2006. A systematic survey of antioxidant activity of 30 Chinese medicinal plants using the ferric reducing antioxidant power assa. Food Chemistry, 97:705-711. 